\title{
Caminhos possíveis: inovações sobre o estudo de projetos de arquitetura em um trabalho acadêmico
}

Possible pathways: Innovations on the study of architecture projects in an academic work

\author{
Gianne Speth ${ }^{1}$ e Samuel Silva de Brito ${ }^{2}$ \\ ${ }^{1}$ Universidade Federal de Santa Maria, Cachoeira do Sul, Brasil \\ gianne_speth@hotmail.com \\ ${ }^{2}$ Universidade Federal de Santa Maria, Cachoeira do Sul, Brasil \\ samuel.brito@ufsm.br
}

\section{Resumo}

Este artigo trata sobre um trabalho coletivo realizado pelos alunos da disciplina "Teoria e História da Arquitetura e Urbanismo $V$ " do Curso de Arquitetura e Urbanismo da UFSM Campus Cachoeira do Sul. A partir da análise de seis edificios escolares, compilou-se a sintese destes estudos de caso de forma inovadora em um livreto-fanzine que, além de procurar dialogar com toda a comunidade acadêmica promovendo discussões entre alunos, professores e técnicos administrativos, buscou a formação de estudantes reflexivos e autônomos com a capacidade de desenvolver processos cognitivos superiores que vão da análise à criação.

Palavras-chave: Livreto-fanzine; Criação coletiva; Plataforma de divulgação

\section{Abstract}

This article deals with a collective work carried out by the students of the subject "Theory and History of Architecture and Urbanism V" of the Course of Architecture and Urbanism of UFSM Campus Cachoeira do Sul. From the analysis of six school buildings, the synthesis of these case studies in an innovative way in a booklet-fanzine that, in addition to seeking dialogue with the entire academic community promoting discussions among students, teachers and administrative technicians, sought the training of reflexive and autonomous students with the capacity to develop higher cognitive processes ranging from analysis to creation.

Keywords: Booklet-fanzine; Collective creation; Broadcast platform 


\section{Introdução}

Desenvolvido em formato livreto-fanzine, o trabalho coletivo realizado pelos alunos da disciplina "Teoria e História da Arquitetura e Urbanismo V" do Curso de Arquitetura e Urbanismo da UFSM Campus Cachoeira do Sul, durante o primeiro semestre de 2017, buscou compilar a síntese de seis estudos de caso de edifícios e projetos de escolas de arte e arquitetura. O trabalho foi realizado em duas fases, uma individual onde cada aluno realizou um estudo aprofundado e apresentação sobre uma obra de arquitetura, e uma segunda fase de criação em grupo, onde elaborou-se uma plataforma de divulgação da síntese destes estudos. A finalização desta etapa de criação coletiva acabou sendo transformada numa aula de lançamento deste novo veículo de comunicação. O principal resultado alcançado foi a editoração conjunta de um livreto-fanzine que, além de assumir o formato digital (pdf) para facilitar a livre veiculação e compartilhamento, teve alguns exemplares impresso (em formato A5 e colorido) e encadernado em mutirão pelos alunos envolvidos.

\section{A disciplina e sua metodologia}

A disciplina "Teoria e História da Arquitetura e Urbanismo V"1 foi ministrada no primeiro semestre de 2017 pelo professor arquiteto e doutor Samuel Brito e frequentada pelos acadêmicos Andreza da Costa, Geanny Bañolas Leal, Gianne Speth, Leonardo Ivo Franceschi, Ramão Camargo Machado e Renata Rodrigues. A estratégia de ensino aplicada na disciplina estruturou um modelo de aprendizagem ativa que explorou o protagonismo dos estudantes na construção dos próprios saberes em conexão com o contexto real, formando pessoas capazes de mobilizar os recursos para agir. Dessa forma, todas as atividades desenvolvidas ao longo do semestre buscaram despertar nos discentes o discernimento da informação, a auto avaliação, a organização coletiva, a criatividade, o discurso, entre outros requisitos.

A metodologia do trabalho da disciplina se dividiu em três etapas: primeiramente atividades introdutórias desenvolvidas em um curto espaço de tempo; uma segunda etapa individual onde cada aluno ficou responsável por realizar a análise de uma obra exemplar de arquitetura escolar com apresentação final em sala para os colegas de disciplina; e uma última etapa de criação coletiva onde os alunos, em sala de aula e com a mediação do professor, decidiram criar uma plataforma de divulgação da síntese destes estudos dirigida a todos da comunidade acadêmica - discentes, docentes e técnicos administrativos.

As atividades introdutórias desenvolvidas na primeira etapa do trabalho eram dinâmicas narrativas que visavam amadurecer a capacidade analítica e a retórica técnica dos alunos. Entre estas dinâmicas estava a descrição de uma casa de valor sentimental para o aluno, onde cada um descrevia uma residência afetiva enquanto os demais deveriam imaginá-la, e após a narração o acadêmico mostrava a planta da edificação para os colegas. A partir dessas atividades introdutórias passou-se para os seis casos de estudo de edifícios e projetos de escolas de arte e arquitetura da modernidade. Os arquitetos estudados, bem como suas escolas foram: Mies Van Der Rohe e Crown Hall; Le Corbusier e The Carpenter Center for Visual Arts; Frank Lloyd Wright e Taliesin West; Lucio Costa e Cidade Universitária do Brasil; Walter Gropius e Bauhaus; João Batista Villanova Artigas e Faculdade de Arquitetura e Urbanismo da USP.

Nesta segunda etapa cada aluno pode desenvolver um estudo aprofundado sobre sua escola, tendo como desfecho a apresentação individual para a turma com a duração de uma hora para cada trabalho. Além disso, houve uma aluna que incrementou sua apresentação com um envolvente jogo lúdico-projetual, transformando dois distintos projetos da Cidade

\footnotetext{
${ }^{1}$ Com o novo Projeto Pedagógico do Curso de Arquitetura e Urbanismo da UFSM-CS, atualmente a disciplina se intitula "História da
} Arquitetura e Urbanismo III". 
Universitária do Brasil em um quebra-cabeça com suas plantas de implantação, exigindo que os participantes da dinâmica distinguissem as peças embaralhadas de cada projeto e após desenvolviam a montagem do jogo, uma reconfiguração projetual que estimula a fixação das diretrizes que organizam aquela forma.

Finalizando essa etapa de coleta de informações, iniciou-se a última etapa, a criação coletiva em que os alunos, em sala de aula e com a mediação do professor, decidiram criar uma plataforma de divulgação da síntese destes estudos dirigida aos demais colegas da comunidade acadêmica (discentes, docentes e técnicos administrativos), valorizando uma linguagem provocativa que auxiliasse na reflexão e amadurecimento dos projetos escolares atualmente em desenvolvimento no campus em construção.

O término da disciplina se deu com a finalização desta etapa de criação coletiva, que acabou sendo transformada numa aula de lançamento deste novo veículo de divulgação dos trabalhos ali realizados. O convite estendeu-se às demais turmas do Curso de Arquitetura e Urbanismo e contou com um clima recreativo e descontraído, tendo sido criado cartazes instigantes para aproximar o público.

\section{Inovações de um trabalho acadêmico}

Com a estratégia de ensino baseada na metodologia do "estudo de caso" - instrumento pedagógico apoiado na estruturação de uma controvérsia exigindo empenho dos envolvidos para identificar questões, analisar evidências, desenvolver argumentos e avaliar soluções - o professor buscou associar à disciplina o desafio de estudar a pertinência atual da solução de projeto de alguns edifícios escolares do período da arquitetura moderna (escopo da ementa), visando o diálogo com a atual realidade vivenciada pela comunidade acadêmica da UFSM em Cachoeira do Sul.

\subsection{Escolha do nome "Novelo: caminhos possíveis"}

Com o campus Cachoeira do Sul ainda em fase de implantação, é perceptível que existem diversas possibilidades construtivas para os futuros prédios, especialmente o do Curso de Arquitetura e Urbanismo. O Campus da UFSM-CS, oficializado em 2013 através da Resolução n038/2013 do Conselho Superior da instituição (Consu) e iniciado em agosto de 2014, oferece cinco cursos de graduação, sendo eles: Arquitetura e Urbanismo, Engenharia Agrícola, Engenharia Elétrica, Engenharia Mecânica e Engenharia de Transportes e Logística. As instalações provisórias da instituição localizam-se em cinco imóveis no centro da cidade, já a sede futura está sendo construída no distrito Passo da Areia e comporta uma área de aproximadamente 84 hectares. A primeira fase de implantação ainda está em andamento e prevê a construção de vários edifícios, entre eles os destinados para os cursos de graduação e moradia estudantil.

A partir do momento vivenciado pelo campus UFSM-CS, que apesar de sua implantação concreta deixa entrever diversos outros caminhos possíveis de se trilhar, e conjuntamente com a experiência inovadora de aprendizagem desenvolvida em sala de aula, o livreto-fanzine foi intitulado "Novelo". Optou-se por esse nome por seu significado traduzir bem a ideia do processo criado, o trabalho tecido através da teia que cada aluno fiou, sendo o novelo esse objeto que recolhe e reúne o grande tramado.

A escolha do nome foi desenvolvida por todos os integrantes da turma, através de um longo debate, em que se tomou como partida as atividades realizadas. Escolheram-se palavras chaves e após optou-se por palavras que representassem toda a ideia tecida. Enfim chegou-se no consenso da palavra "novelo" como a melhor tradução do trabalho tramado, bem como a 
relação com o cenário atual do campus, enquanto o subtítulo "caminhos possíveis" reforçava a sugestão de refletirmos sobre novas possibilidades projetuais, assim como a aplicabilidade de algumas daquelas propostas em análise no livreto-fanzine.

\subsection{Edição do livreto-fanzine}

A edição do fanzine ocorreu de forma colaborativa entre todos os alunos da disciplina. O formato de um fanzine em livreto, em paisagem e tamanho A5, foram opções de layout escolhidos com o objetivo de criar um modelo de revista não científica, buscando um modelo excessivamente gráfico e de fácil manuseio e com a intenção de atrair a atenção dos leitores. A editoração foi desenvolvida em sala de aula, e cada aluno ficou responsável por um capítulo. Para que houvesse uma identidade visual na edição do livreto, foi seguido um modelo de layout pré-estabelecido pela turma.

Figura 1 - Editoração do folheto-fanzine, a figura 1 (a) mostra os cartazes provocativos criados durante o desenvolvimento da revista e figura 1 (b) mostra a produção do novelo realizada em sala de aula.

(a)

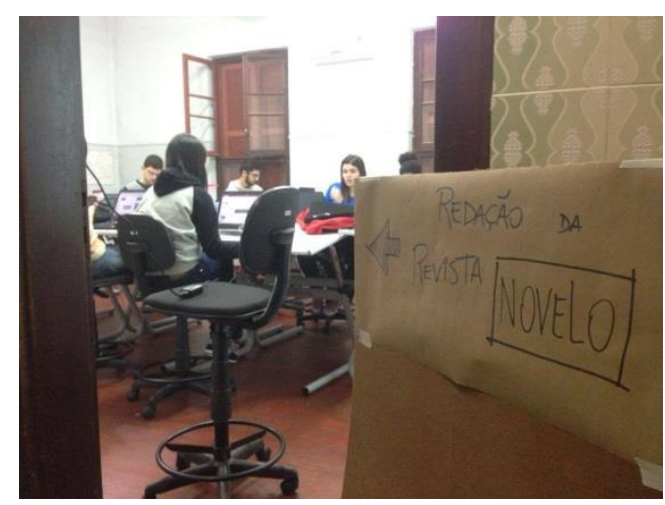

(b)

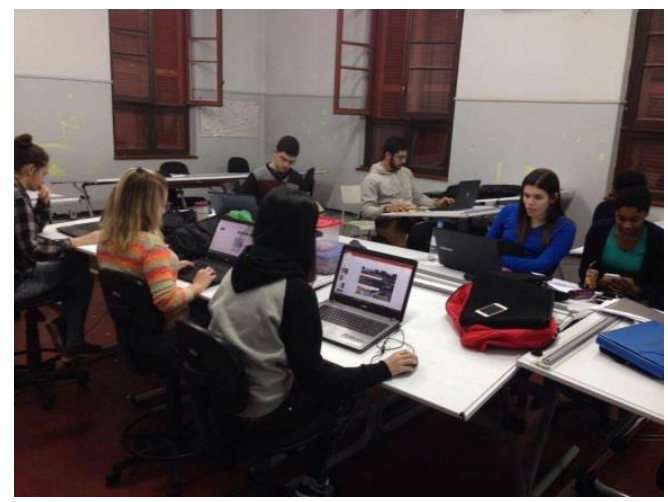

Buscou-se valorizar uma linguagem provocativa em toda narrativa da revista. Dessa forma, cada capítulo explorou um subtítulo instigante afim de atrair a leitura do público. Além disso, as imagens apresentadas foram criteriosamente selecionadas pois são figuras que melhor representam o conjunto de informações referentes a escola estudada, bem como que melhor se adequavam à proposta de excitar a leitura.

Figura 2 - Páginas iniciais do primeiro estudo de caso.

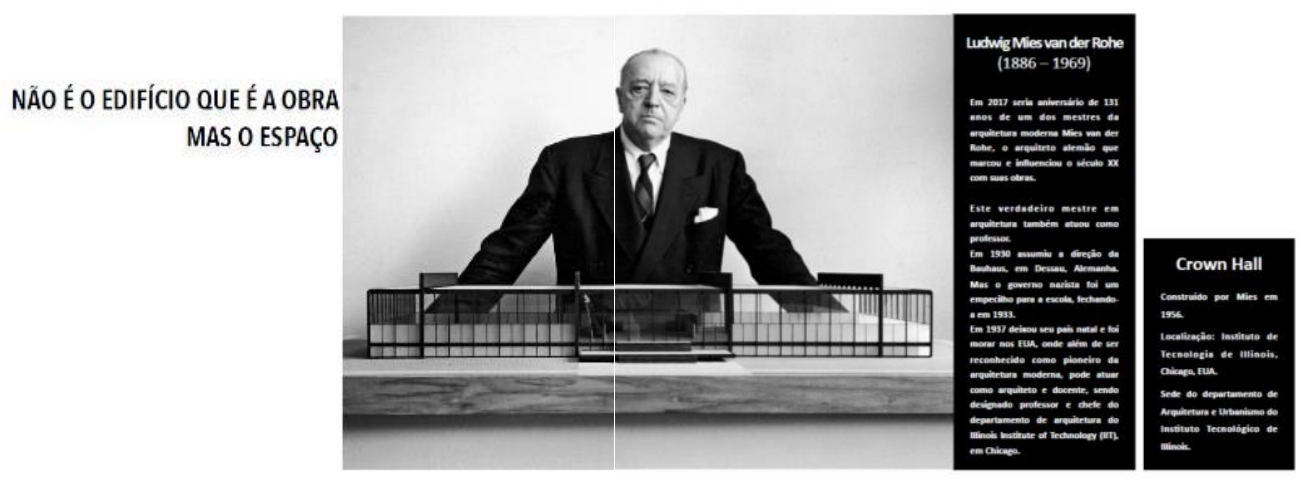


Figura 3 - Páginas iniciais do segundo estudo de caso

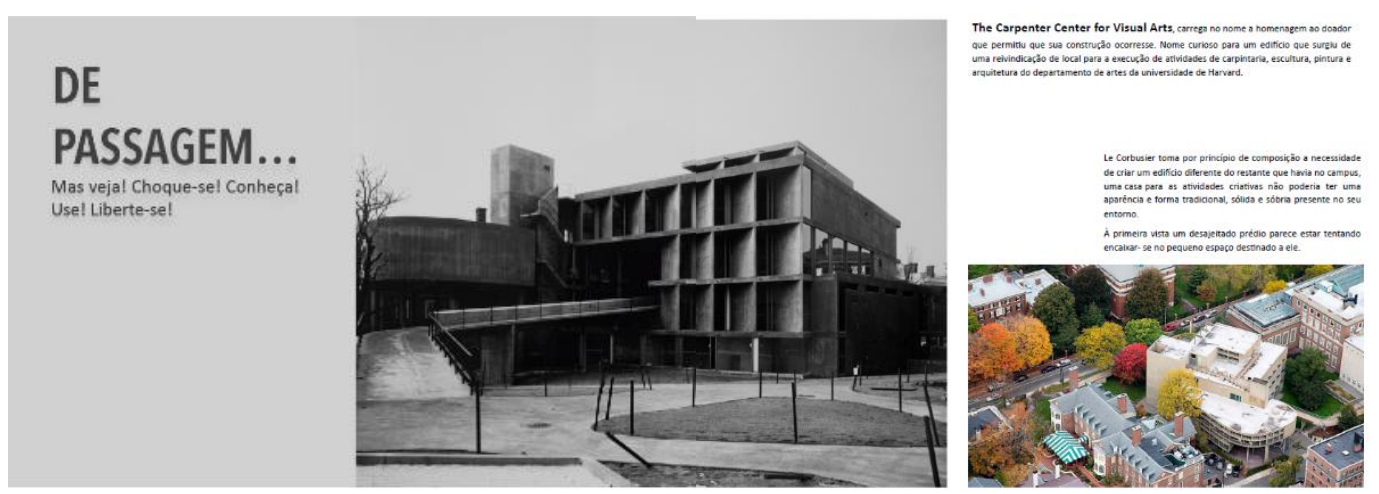

Figura 4 - Páginas iniciais do terceiro estudo de caso

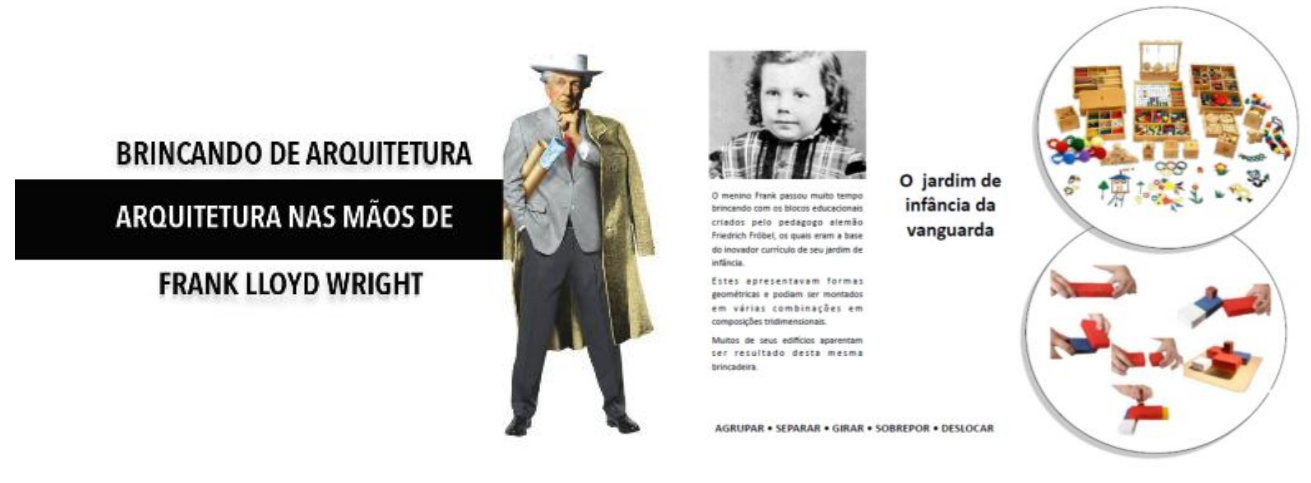

Figura 5 - Páginas iniciais do quarto estudo de caso
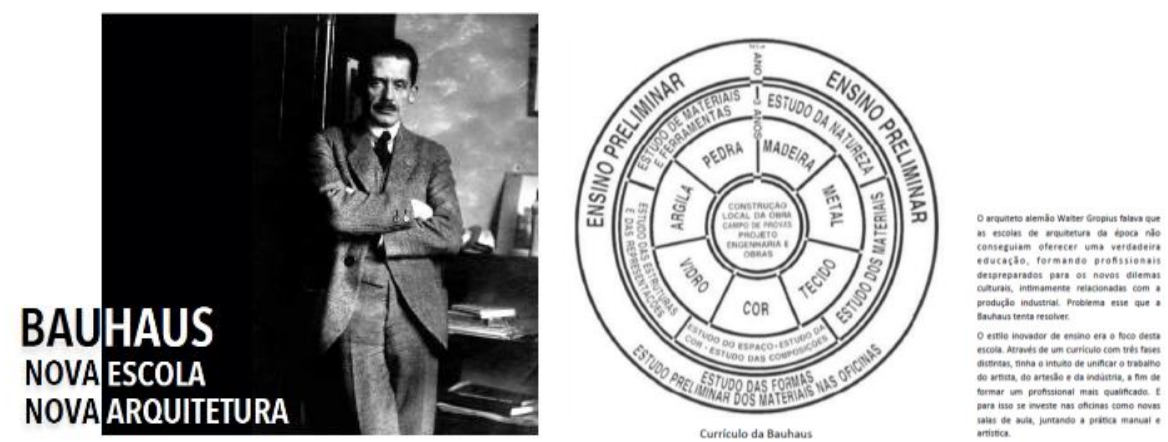

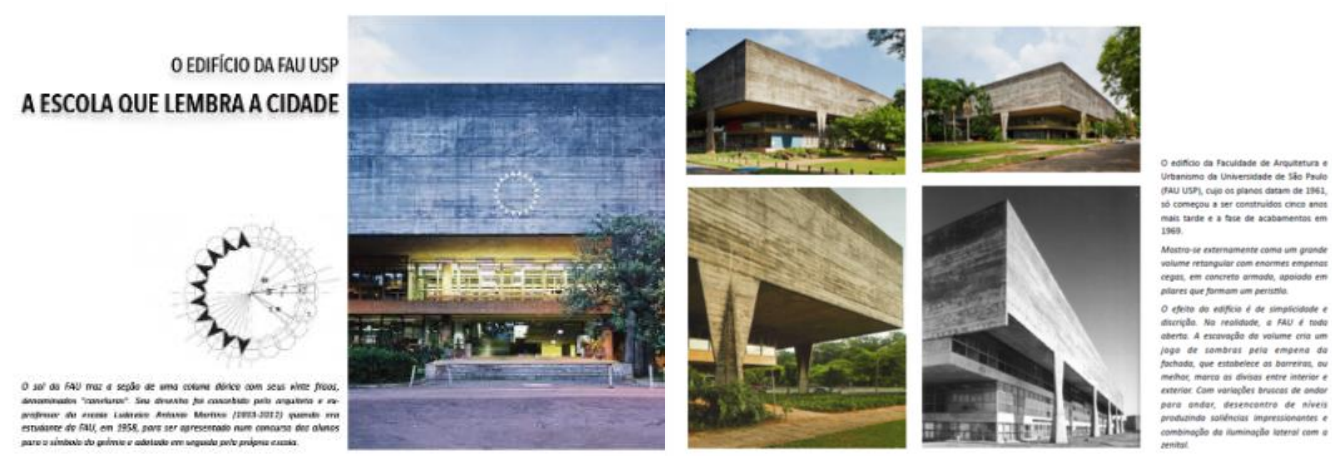

Figura 7 - Páginas iniciais do sexto estudo de caso
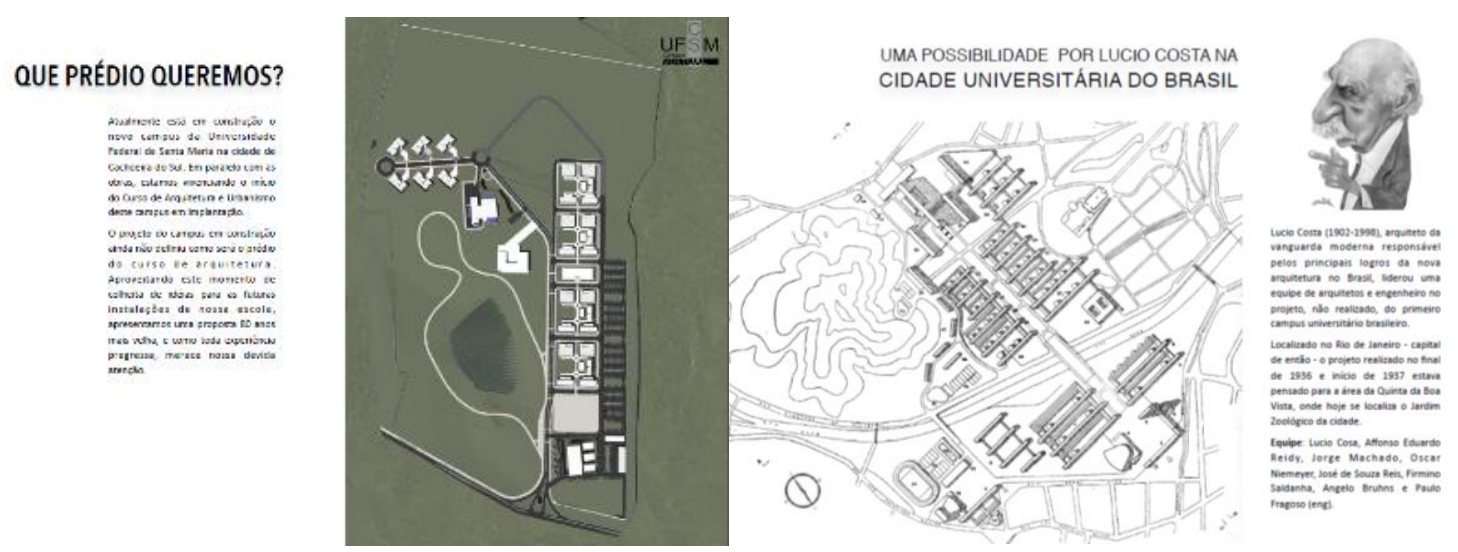

Foi impresso um exemplar para cada aluno, um para o professor e um modelo ofertado a biblioteca do campus. Esses exemplares foram impressos em formato A5 e colorido. A impressão e encadernação foi realizada em mutirão pelos envolvidos juntamente com o professor. Além do formato físico foi desenvolvido o formato digital (pdf) para facilitar a livre veiculação e compartilhamento do conhecimento com toda a comunidade acadêmica (discentes, docentes e técnicos administrativos).

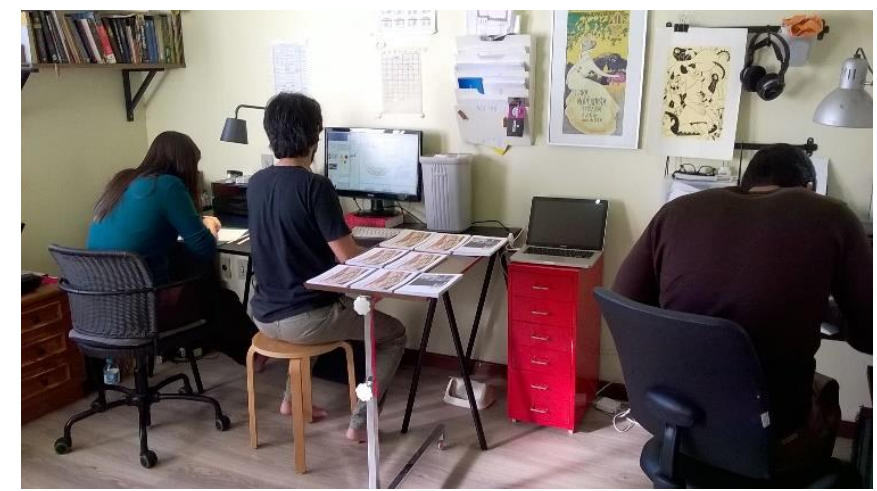


Figura 9 - Capa do livreto-fanzine, formato A5

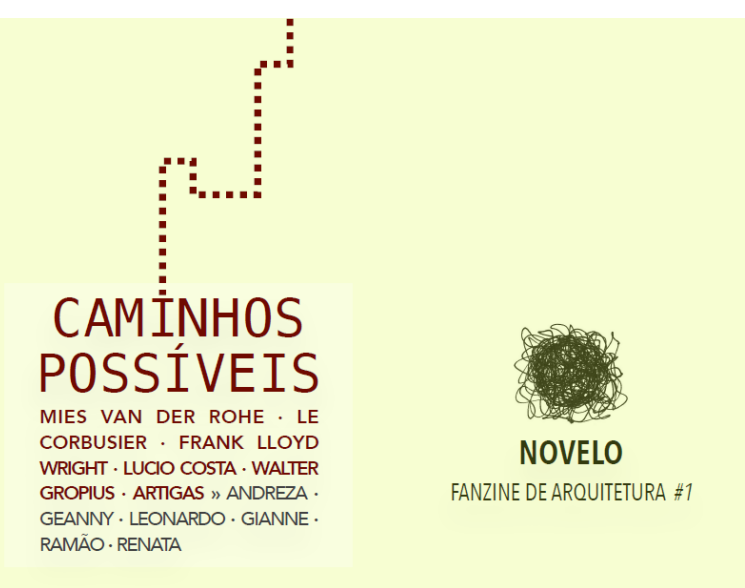

\subsection{Divulgação}

O lançamento e divulgação do fanzine ocorreu no último dia de aula. O evento contou com a participação dos membros da turma e também se estendeu aos demais alunos e professores do campus. Afim de divulgar e atrair os convidados foram feitos cartazes instigantes, tais como: "Tramando Conhecimento"; "Venha Buscar o seu Novelo"; "Lançamento LivretoFanzine, Venha". Além disso, estabeleceu-se um clima descontraído com música, roda de conversa, troca de experiência e coquetel.

Figura 5 - Lançamento do folheto-fanzine, a figura 5 (a) mostra os cartazes provocativos desenvolvidos no lançamento da revista. Figura 5 (b) mostra a integração dos estudantes e figura 5 (c) mostra a exposição dos livretos

(a)

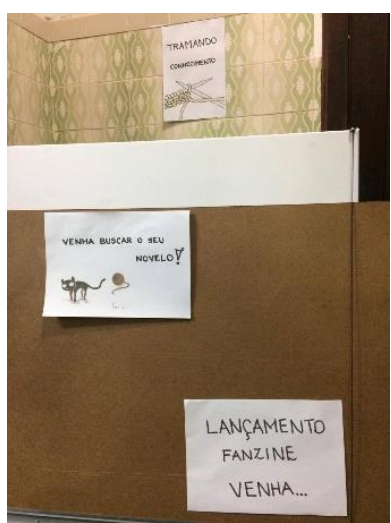

(b)
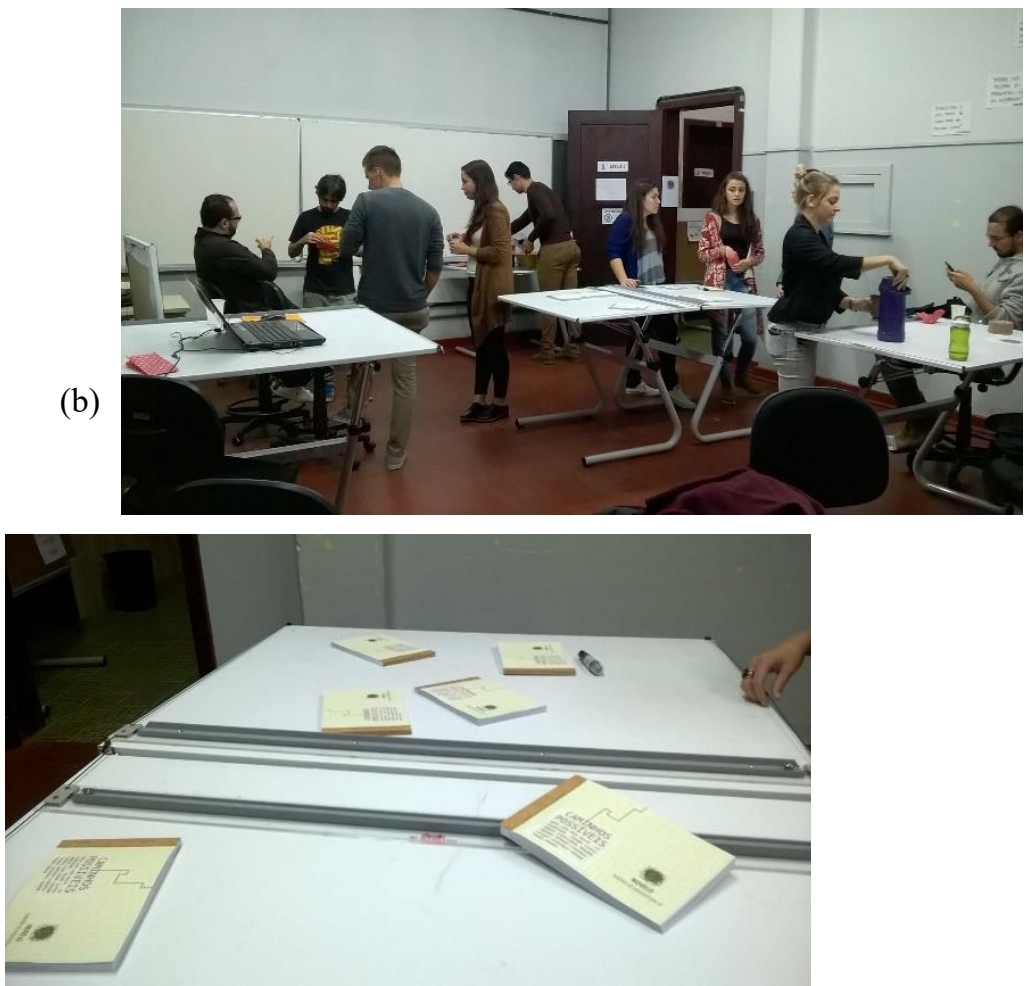

(c) 


\section{Considerações finais}

Embora o objetivo do trabalho realizado na disciplina não tenha sido buscar a novidade metodológica, o arrojo empreendedor dos alunos acabou tornando esta inovação um resultado inevitável. A procura por uma aprendizagem ativa que explorasse o protagonismo dos estudantes na construção dos próprios saberes em conexão com o contexto real, resultou: na formação de estudantes reflexivos e autônomos, capazes de mobilizar os seus recursos para agir; elaboração de plataformas de divulgação que deram acessibilidade do conteúdo produzido dentro de uma disciplina; diálogo com o coletivo acadêmico promovendo discussões entre alunos, professores e técnicos administrativos; produção bibliográfica (não científica - formato fanzine), com reflexão disciplinar sobre caminhos possíveis para projetos de prédios institucionais em construção.

\section{Referências}

JONES, Peter Blundell; CANNIFFE, Eamonn. Modelos de La Arquitectura Moderna: Monografias de Edifícios Ejemplares 1945-1990. Vol.2. Barcelona: Reverté, 2013.

ZEIN, Ruth Verde. A síntese não é ponto de chegada, mas de partida. In: LARA, F.; MARQUES, S. (org).

Projetar/Desafios e conquistas da pesquisa e do ensino de projeto. Rio de Janeiro: EVC Editora, 2003, p. 83.

MONEO, Rafael. Inquietação Teórica e Estratégia Projetual. São Paulo: Cosac \& Naify, 2008.

UNWIN, Simon. Vinte edifícios que todo arquiteto deve compreender. São Paulo: Martins Fontes, 2013. 